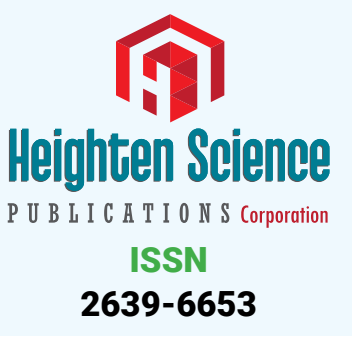

*Address for Correspondence: Muhammad Azhar, MBBS, CMH Medical and Dental College, Lahore, Pakistan, Tel: 092-307-2578263; Fax: 092 62-9255243; Email: dr.azharalvi003@gmail.com

Submitted: 11 May 2018

Approved: 10 September 2018

Published: 11 September 2018

Copyright: @ 2018 Ahmad I, et al. This is an open access article distributed under the Creative Commons Attribution License, which permits unrestricted use, distribution, and reproduction in any medium, provided the original work is properly cited

Keywords: Liver; Inflammatory disorder; Metabolic disorder; Biopsy; Etiology; Cirrhosis

Check for updates

\title{
Evaluation of unexplained clinical features of hepatic diseases through biopsies among hospitalized children: A cross-sectional study in Lahore, Pakistan
}

\author{
Ibtasam Ahmad', Muhammad Haris ${ }^{1}$, Amnah Javed ${ }^{1}$ and \\ Muhammad Azhar ${ }^{2 *}$ \\ ${ }^{1} \mathrm{FMH}$ College of Medicine and Dentistry, Lahore, Pakistan \\ ${ }^{2} \mathrm{CMH}$ Medical and Dental College, Lahore, Pakistan
}

\section{Abstract}

Objectives: There are variations in therapeutic regimens of different liver diseases. The accurate diagnosis ensures prompt recovery from these diseases. The present study aimed to evaluate the underlying causes of unexplained signs and symptoms associated with liver diseases through biopsies.

Methods: A retrospective study was conducted in a public child care specialty of Lahore, Pakistan. The data was collected from medical records of the patients who were index hospitalized with unexplained clinical presentation of liver disease between 1st July, 2017 and 31st December, 2017. Data were analyzed by using Statistical Packages for Social Sciences (IBM SPSS Statistics for Windows, Version 21.0. Armonk, NY: IBM Corp.), and Microsoft Excel (MS Office 2010).

Results: Overall, the records of 53 patients were selected for the study. Most of them were 11 to 15 years of age. The patients were presented with unexplained hepatomegaly $(60.4 \%)$ and jaundice (40.7\%) during index hospitalization which made them eligible for liver biopsy (LB). The findings of LB revealed that the underlying causes of liver diseases in most of the cases were metabolic $(33.9 \%)$ and inflammatory disorders $(22.6 \%)$. Majority of the patients were $\leq 4$ years of age, however cryptogenic cirrhosis $(39.1 \%)$ was commonly found in $>10$ years of age. Although most of the patients were suffering from metabolic disorders ( $p$-value $=0.07)$ and liver cirrhosis ( $p$-value $=0.08)$ but these were not statistically significant.

Conclusion: LB was beneficial in evaluating the etiologies of unexplained signs and symptoms of liver diseases. It was found that glycogen storage diseases and liver cirrhosis were the most common etiologies of liver diseases among pediatric patients. But etiologies like metabolic and inflammatory diseases were insignificantly associated with gender.

\section{Introduction}

Children are at high risk of developing liver diseases but the level of severity is different in each case. Such patients are presented with elevated liver function tests (LFTs) [1]. The standard technique in diagnosis of various pediatric liver diseases is histopathological examination of tissue i.e. Liver biopsy (LB) [2]. The liver injury among children is primarily the result of various metabolic, developmental and infectious disorders which may lead to mortality or life-threatening morbidities [3]. There are different treatment options available for each pediatric liver disease [4]. The percutaneous approach of LB is used to identify pediatric hepatic problems [5]. An accurate and prompt diagnosis is essential for proper disease management. For 
instance, if a child presents with cholestasis then an accurate diagnosis is necessary to differentiate between idiopathic neonatal hepatitis (INH) and biliary atresia (BA). This is because of the reason that INH can be treated with pharmacological therapies while early surgical methods are crucial for BA [6]. Also, LB is beneficial in differentiating among cholestasis, hepatitis, steatosis, vascular abnormalities, infiltrative disorders, infectious and metabolic diseases on the basis of histopathological features [7]. This technique is not only useful in diagnosis of primary hepatobiliary disorders, and secondary problems but also gives a clear representation of prognosis of various hepatic diseases $[8,9]$. The immune-mediated complications and genetic disorders can be detected through LB on the basis of Immuno histochemical (IHC) procedures [10]. The beneficial aspects of LB can be increased by overcoming several limitations like inadequate sample size and inappropriate correlation of hepatic morphology and medical history $[11,12]$.

The present study aimed to evaluate the underlying causes of the unexplained signs and symptoms associated with liver diseases through biopsies among pediatric patients.

\section{Materials and Methods}

\section{Study design and setting}

A retrospective, cross-sectional study was conducted in a public child care specialty of Lahore, Pakistan. The selected setting was a tertiary care hospitals with liver and gastroenterology departments where health services are provided to the children $(<18$ years of age). The characteristics of the selected hospital were summarized in table 1.

\section{Study population and sample size}

The records of 114 patients admitted in liver and gastroenterology wards were scrutinized. The patients were included in the study if they were 1 month to 15 years of age, index hospitalized, presented with clinical features associated with liver diseases, not suffering from any drug induced liver disease and acute or chronic disorder, had unexplained abnormal results of LFTs, never underwent liver transplant and had gone through ultrasound-guided percutaneous LB using spring cut semi-automated needle. The records of 53 patients fulfilled our inclusion criteria and consequently selected for the study.

\section{Data collection}

A data collection tool was used to collect the data. The questionnaire was structured and consisted on four parts: 1) general characteristics (age and gender) of the patient, 2) clinical sign and symptoms, 3) findings of other unexplained abnormal results of tests (coagulation profile, ultrasound, complete blood count (CBC) and LFTs), and 4) histopathological findings of LB.

Data were collected between $1^{\text {st }}$ July, 2017 and $31^{\text {st }}$ December, 2017 according to the objectives of the study. The investigational team included general medical practitioner and a trained nurse. All the investigators received the same training prior to the survey

Table 1: Characteristics of the selected hospital.

\begin{tabular}{|c|c|c|}
\hline Sr. no. & Characteristics & N \\
\hline 1 & Number of beds & 1,100 \\
\hline 2 & Outpatients visit last year & $1,049,792$ \\
\hline 3 & Inpatients visit last year & 151,736 \\
\hline 4 & Physicians/Medical officers & 252 \\
\hline 5 & Pharmacists/Dispensers & 22 \\
\hline 6 & Nurses & 229 \\
\hline 7 & Other Paramedical staff* & 1,832 \\
\hline
\end{tabular}


for the collection and validation of data. During the survey, one investigator filled out the investigational form and the other reviewed the data. The expert opinion of an experienced radiologist and histopathologist was also taken into account when needed.

\section{Data analysis}

The descriptive statistics (frequencyand percentage) were applied on characteristics of study population, etiologies and histopathological findings. The frequencies of each etiology were calculated separately and in combination with the age group or gender. The significance of the data was evaluated by Fisher's exact test and Chi square test taking $\mathrm{p}<0.05$ as the value of significance. Data were analyzed by using Statistical Packages for Social Sciences (IBM SPSS Statistics for Windows, Version 21.0. Armonk, NY: IBM Corp.) and Microsoft Excel (MS Office 2010).

\section{Ethical approval}

Ethical approval was obtained from the Medical Research Ethics Committee (MREC) of Nishtar Medical College, Multan (Reference: 05-2017/REC, dated May 11, 2017). The permission to conduct this study was also obtained from the administrator of the healthcare setting.

\section{Results}

The medical records of 53 patients were investigated for the study. Among them, $69.8 \%(n=37)$ were male, $43.4 \%(n=23)$ were of age 11 to 15 years and $73.6 \%(n=39)$ were presented with more than 4 signs and symptoms of liver disease (Table 2).

Overall, 81.1\% ( $\mathrm{n}=43)$ were presented with hepatomegaly, $60.4 \%(\mathrm{n}=32)$ with jaundice and $47.2 \%(n=25)$ with splenomegaly. While $35.9 \%(n=19)$ were found with unexplained abnormal LFTs especially levels of hemoglobin and serum bilirubin (Table 3).

The histopathological findings after LB revealed that metabolic 33.9\% $(n=18)$ and inflammatory $22.6 \%(n=12)$ disorders were the most common underlying causes of liver diseases. Among them, 13.2\% (n=7) of the cases were found with glycogen storage disease and $9.4 \%(n=5)$ were having liver cirrhosis, respectively (Table 4).

In patient's $\leq 10$ years of age, metabolic storage disorders were most commonly found while among $>10$ years of age inflammatory hepatitides was the most commonly found etiology (Table 5).

There was no significant difference observed among pediatric patients on the basis of gender ( $p$-value $>0.05$ ). Although most of the patients were suffering from metabolic disorders ( $p$-value $=0.07)$ and liver cirrhosis $(p$-value $=0.08)$ but these were not statistically significant (Table 6).

\section{Discussion}

The findings of current study revealed that metabolic and inflammatory disorders were the major etiologies among pediatric patients having unexplained clinical features of hepatic disease. Percutaneous LB is a safe and efficacious method in early detection of disease and prior to initiate the therapeutic regimen.

Table 2: Characteristics of study population.

\begin{tabular}{|c|c|c|}
\hline \multicolumn{2}{|c|}{ Indications of biopsy } & $\mathbf{N}(\%)$ \\
\hline \multirow{2}{*}{ Gender } & Male & $37(69.8)$ \\
\cline { 2 - 3 } & Female & $16(30.2)$ \\
\hline \multirow{2}{*}{ Age } & 1 month - 4 years & $19(35.9)$ \\
\hline \multirow{2}{*}{ Clinical signs and symptoms } & $5 y e a r s-10$ years & $11(20.8)$ \\
\cline { 2 - 3 } & 11 years - 15 years & $23(43.4)$ \\
\hline
\end{tabular}




\begin{tabular}{|c|c|c|}
\hline \multicolumn{2}{|c|}{ Cause } & $\mathbf{N}(\%)$ \\
\hline \multicolumn{2}{|c|}{ Ascites } & $21(39.6)$ \\
\hline \multicolumn{2}{|c|}{ Fever } & $8(15.1)$ \\
\hline \multicolumn{2}{|c|}{ Jaundice } & $32(60.4)$ \\
\hline \multicolumn{2}{|c|}{ Variceal bleed } & $7(13.2)$ \\
\hline \multicolumn{2}{|c|}{ Anemia } & $15(28.3)$ \\
\hline \multicolumn{2}{|c|}{ Splenomegaly } & $25(47.2)$ \\
\hline \multicolumn{2}{|c|}{ Hepatomegaly } & $43(81.1)$ \\
\hline \multicolumn{2}{|c|}{ Spider hemangioma } & $4(7.5)$ \\
\hline \multicolumn{2}{|c|}{ Hemostasis } & $16(30.2$ \\
\hline \multicolumn{2}{|c|}{ Palmar erythema } & $3(5.7)$ \\
\hline \multicolumn{2}{|c|}{ Lab test results } & $19(35.9)$ \\
\hline \multirow{2}{*}{ Hemoglobin } & $<7 \mathrm{Gm} \%$ & $2(3.8)$ \\
\hline & $>7 \mathrm{Gm} \%$ & $3(5.7)$ \\
\hline \multirow{2}{*}{ Serum bilirubin } & $1-3 \mathrm{mg} \%$ & $4(7.6)$ \\
\hline & $>3 \mathrm{mg} \%$ & $1(1.9)$ \\
\hline $\mathrm{SGPT}^{*}$ & $>801 \mathrm{I} / \mathrm{L}$ & $2(3.8)$ \\
\hline Serum albumin & $<2.5 \mathrm{Gm} \%$ & $4(7.6)$ \\
\hline $\mathrm{PT}^{+}$ & $>4$ seconds & $3(5.7)$ \\
\hline
\end{tabular}

${ }^{\star}$ Serum glutamic pyruvic transaminase, ${ }^{\dagger}$ Prothrombin time.

Table 4: Histopathological findings after liver biopsies.

\begin{tabular}{|c|c|}
\hline Liver disorder & $\mathbf{N}(\%)$ \\
\hline \multicolumn{2}{|l|}{ Metabolic disorders $(33.9 \%, \mathrm{n}=18)$} \\
\hline Glycogen storage & $7(13.2)$ \\
\hline Non-glycogen storage & $5(9.4)$ \\
\hline Progressive familial intra hepatic cholestasis (PFIC) & $4(7.5)$ \\
\hline Alpha 1 antitrypsin & $2(3.8)$ \\
\hline \multicolumn{2}{|l|}{ Inflammatory disorders $(22.6 \%, \mathrm{n}=12)$} \\
\hline Chronic Hepatitis & $5(9.4)$ \\
\hline Autoimmune hepatitis & $2(3.8)$ \\
\hline $\mathrm{INH}$ & $3(5.7)$ \\
\hline Acute on chronic hepatitis & $1(1.9)$ \\
\hline Non specific & $1(1.9)$ \\
\hline \multicolumn{2}{|l|}{ Developmental disorders $(13.2 \%, n=7)$} \\
\hline BA & $4(7.6)$ \\
\hline Alagille syndrome & $2(3.8)$ \\
\hline Vanishing bile duct syndrome & $1(1.9)$ \\
\hline \multicolumn{2}{|l|}{ Malignancies $(7.5 \%, n=4)$} \\
\hline Primary(hepatoblastoma) & $3(5.7)$ \\
\hline Metastatic & $1(1.9)$ \\
\hline \multicolumn{2}{|l|}{ Miscellaneous etiologies $(16.9 \%, n=9)$} \\
\hline Cryptogenic cirrhosis & $9(16.9)$ \\
\hline \multicolumn{2}{|l|}{ Vascular abnormalities $(5.7 \%, n=3)$} \\
\hline Acute portal vein obstruction & $3(5.7)$ \\
\hline Total & $53(100)$ \\
\hline
\end{tabular}

Table 5: Etiologies of liver diseases among different age groups.

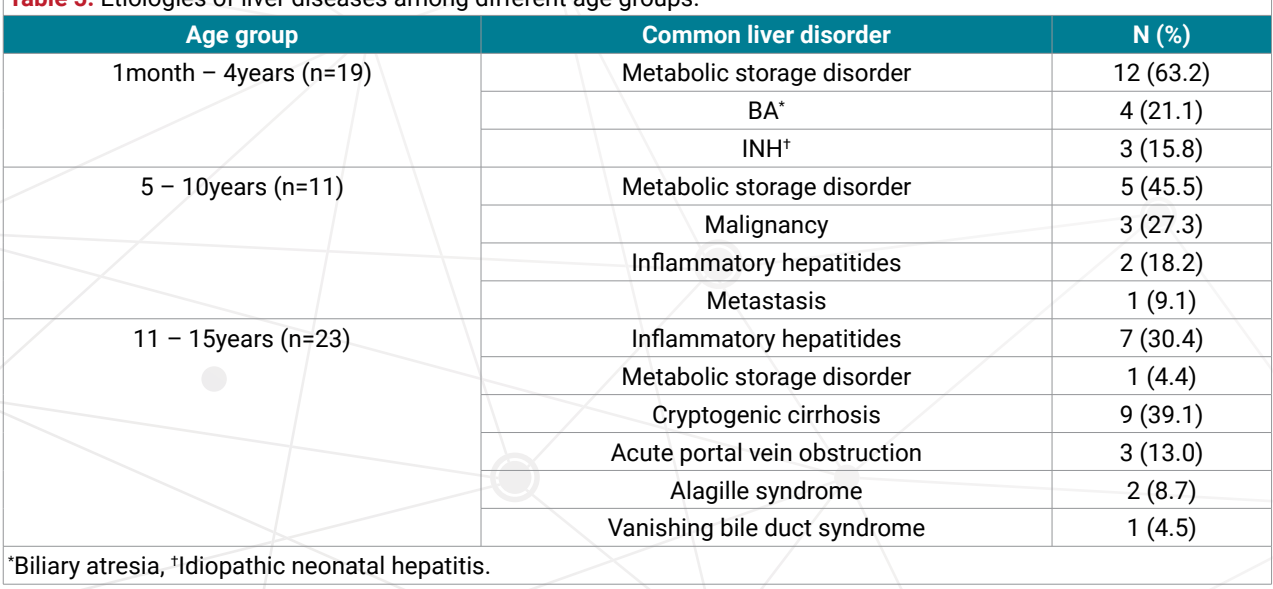




\begin{tabular}{|c|c|c|c|}
\hline Table 6: Statistical association of etiologies with gender. & Female N (\%) & p-value \\
\hline Etiologies & Male N (\%) & $7(13.2)$ & 0.07 \\
\hline Metabolic disorders & $11(20.8)$ & $3(5.7)$ & 0.4 \\
\hline Inflammatory disorders & $9(16.9)$ & $2(3.8)$ & 0.4 \\
\hline Developmental disorders & $5(9.4)$ & 0 & 0.2 \\
\hline Malignancy & $4(7.6)$ & $3(5.7)$ & 0.08 \\
\hline Cirrhosis & $6(11.3)$ & $1(1.9)$ & 0.2 \\
\hline Vascular abnormalities & $2(3.8)$ & & \\
\hline
\end{tabular}

This method evaluates extent of liver injury and gives valuable information when clinical features (e.g., hepatomegaly) and other diagnostic tests (e.g., LFTs) provide unexplained results [13]. The incidence of hepatic diseases among pediatric patients is inconsistent with age e.g., autoimmune, infective and infiltrative causes are common in pediatric patients of older age groups while BA and INH are more prevalent among younger patients. The underlying causes of hepatic disorders depend on various factors like the particular characteristics of study population, accessibility of diagnostic facilities and trends in medical practices. The present study revealed that metabolic and inflammatory disorders were among the underlying causes of liver diseases among pediatric patients. A Pakistani study revealed hemochromatosis as an etiology behind liver injury among $30 \%$ of the study population [14]. The possible explanation of it might be the referral pattern because many patients underwent bone marrow transplantation. Another study found neonatal hepatitis among $20.3 \%$ of the pediatric patients which is quite high in comparison of the present study [15]. This is due to the referral pattern as the patient load in the current study setting was very high.

The incidence of liver disorders is also dependent on geographical variations and characteristics of study population. A study conducted on 51 children in India having 2 days to 12 years of age revealed glycogen storage diseases (GSD) and metabolic disorders as the underlying causes among many sufferers of Wilson's disease [13]. The prompt diagnosis of asymptomatic patients and the genetic counselling of parents can be beneficial in decreasing prevalence of these diseases in the future [16]. Among the previously published studies, the variation in the incidence of chronic hepatitis is in the range of $<10 \%$ to $>90 \%[15,17-19]$. While in a Nigerian study Schistosomiasis $(37.5 \%)$ was found to be the most common etiology of hepatic diseases especially in tropical regions [20].

The liver cirrhosis is attributed to end-stage hepatic disease. It is characterized as degeneration of parenchymal cells, hepatic fibrosis, nodular regeneration and portal hypertension. The incidence of liver cirrhosis is found to be more common in developing countries as compared to underdeveloped regions (e.g., Pakistan) [21]. Similarly, liver cirrhosis was found in $16.9 \%$ of the study population in the current study. The variation of $10 \%$ to $41.8 \%$ has been found in the reported incidence of cirrhosis among previously published studies [14, 22-24]. The onset of cirrhosis can be prevented if the accurate and prompt diagnosis is made possible of high risk population (e.g., younger age group). Irrespective of age and extent of hepatic injury, many metabolic and genetic diseases may cause harmful effects on liver. Hence, the advancement in the field of genetics is pivotal in finding pathophysiology and new diagnostic strategies for inherited hepatic disorders [25].

\section{Strength and Limitations}

The present study shows the efficiency of percutaneous liver biopsy technique in evaluating the unexplained sign, symptoms and abnormal results of other diagnostic tests among patients suffering from liver diseases.

The findings of present study cannot be generalized to entire country because of the small sample size and shortened length of study period.

As the data is retrospective in nature so the outcomes of LB can't be evaluated. 


\section{Conclusion}

The present study concluded that histopathological findings during biopsy was beneficial in evaluating the etiologies of unexplained signs and symptoms of liver diseases. Metabolic and inflammatory disorders were the most common etiologies ofliver diseases among these patients. But these etiologies showed no significant association with age and gender. Hence, the efficient management of liver diseases demands the facility of prompt and accurate diagnosis for patients especially of high risk population.

\section{Acknowledgement}

We would like to appreciate the help from the hospital staff for their help in data retrieving.

\section{References}

1. Litten JB, Tomlinson GE. Liver tumors in children. The oncologist. 2008; 13: 812-820. Ref.: https://goo.gl/Ggavf6

2. Dezsőfi A, Baumann U, Dhawan A, Durmaz O, Fischler B, et al. Liver biopsy in children: position paper of the ESPGHAN Hepatology Committee. J Pediatr Gastroenterol Nutr. 2015; 60: 408-420. Ref.: https://goo.gl/hfNmfj

3. Mehnaz A, Billo AG, Zuberi SJ. Liver disorders in children. Journal of Pakistan Medical Association. 1990; 40: 62-64. Ref.: https://goo.gl/Rbcqze

4. Dehghani SN, Haghighat M, Imanieh MH, Geramizadeh B, Eskandari Z, et al. Percutaneous Needle Biopsy in the diagnosis of liver diseases in children. Journal of Comprehensive Pediatrics, 2013; 4 : 184-188. Ref.: https://goo.gl/br2ug7

5. Bezerra JA, Balistreri WF. Cholestatic syndromes of infancy and childhood. Semin Gastrointest Dis. 2001; 12: 54-65. Ref.: https://goo.gl/5xmfBP

6. Dehghani SM, Haghighat M, Imanieh MH, Geramizadeh B. Comparison of different diagnostic methods in infants with cholestasis. World J Gastroenterol. 2006; 12: 5893-5896. Ref.: https://goo.gl/zRpnf6

7. Ovchinsky N1, Moreira RK, Lefkowitch JH, Lavine JE. The liver biopsy in modern clinical practice: a pediatric point-of-view. Adv Anat Pathol. 2012; 19: 250-262. https://goo.gl/Q6s4wh

8. Alswat KA, Mumtaz K, Jafri W. Liver biopsy for histological assessment: the case in favor. Saudi journal of gastroenterology: official journal of the Saudi Gastroenterology Association. 2010; 16: 133-139. Ref.: https://goo.gl/RUo5ZW

9. Dezsőfi A, Knisely AS. Liver biopsy in children 2014: Who, whom, what, when, where, why? Clin Res Hepatol Gastroenterol. 2014; 38: 395-398. Ref.: https://goo.gl/xorJ5H

10. Van Ha TG. Liver biopsy in liver transplant recipients. in Seminars in interventional radiology. 2004 Copyright $\odot 2004$ by Thieme Medical Publishers, Inc., 333 Seventh Avenue, New York, NY 10001, USA. Ref.: https://goo.gl/eBJFp8

11. Czaja AJ, Carpenter HA. Optimizing diagnosis from the medical liver biopsy. Clin Gastroenterol Hepatol. 2007; 5: 898-907. Ref.: https://goo.gl/GWc3hN

12. Karim AB, Rahman MM. Safety of blind liver biopsy. The Indian Journal of Pediatrics. 2004; 71: 899901. Ref.: https://goo.gl/ASauEH

13. Govender $\mathrm{P}$, Jonas MM, Alomari Al, Padua HM, Dillon BJ, et al. Sonography-guided percutaneous liver biopsies in children. American Journal of Roentgenology. 2013; 201: 645-650. Ref.: https://goo.gl/B1zG2B

14. Ahmad M, Afzal S, Roshan E, Mubarik A, Bano S, et al. Usefulness of needle biopsy in the diagnosis of pediatric liver disorders. J Pak Med Assoc. 2005; 55: 24-28. Ref.: https://goo.gl/xBPLmD

15. Cheema H, Parkash A, Suleman H, Fayyaz Z. Safety of Outpatient Blind Percutaneous Liver Biopsy (OBPLB) in Children and to Document the Spectrum of Pediatric Liver Disease. Pak Pediatr J. 2015; 39: 12-18. Ref.: https://goo.gl/9whfEQ

16. Roy A, Samanta T, Purkait R, Mukherji A, Ganguly S. Etiology, clinical spectrum and outcome of metabolic liver diseases in children. J Coll Physicians Surg Pak. 2013; 23: 194-198. Ref.: https://goo.gl/7cnRej

17. Anwar $C$, Khalilullah. A histological study of clinically unexplained hepatomegaly in children. Pak $J$ Pathol. 1990; 1: 79-82. 
18. Monajemzadeh M, Tabriz HM, Mahjoub F, Fallahi G, Farahmand F. Liver needle biopsy in Iraninan pediatric patients: diagnostic significance and pattern of liver diseases. Indian $\mathrm{J}$ Pathol Microbiol. 2009; 52: 10-13. Ref.: https://goo.gl/Hw8E2t

19. Zhang HF, Yang XJ, Zhu SS, Zhao JM, Zhang TH, et al. Pathological changes and clinical manifestations of 1020 children with liver diseases confirmed by biopsy. Hepatobiliary Pancreat Dis Int. 2004. 3: 395-398. Ref.: https://goo.gl/ahpCdP

20. Obafunwa J, Elesha S. Childhood liver diseases in Jos, Nigeria: a retrospective histopathological study. East Afr Med J. 1991; 68: 702-706. Ref.: https://goo.gl/G2ai5z

21. Ullah F, Khan S, Afridi AK, Rahman SU. Frequency of different causes of cirrhosis liver in local population. Gomal Journal of Medical Sciences. 2012; 10. Ref.: https://goo.gl/zMF8ws

22. Ahmed T. Evaluation of liver biopsy in undiagnosed cases of liver enlargement. Pak Paedtr J. 1988; 3: $171-175$.

23. Shakoor K. Histological diagnosis of paediatric liver diseases. Pak Paediatr J. 1987; 2: 73-80.

24. Dhole SD, Kher AS, Ghildiyal RG, Tambse MP. Chronic Liver Diseases in Children: Clinical profile and Histology. J Clin Diagn Res. 2015; 9: SC04-07. Ref.: https://goo.gl/iwS2KE

25. Scorza M, Elce A, Zarrilli F, Liguori R, Amato F, et al. Genetic diseases that predispose to early liver cirrhosis. Int J Hepatol. 2014; 2014. 713754. Ref.: https://goo.gl/unvH2Q 